\title{
Patterns of alcohol consumption in 10 European countries participating in the European Prospective Investigation into Cancer and Nutrition (EPIC) project
}

\author{
S Sieri ${ }^{1, *}$, A Agudo ${ }^{2}$, E Kesse $^{3}$, K Klipstein-Grobusch ${ }^{4}$, B San-José ${ }^{5}$, AA Welch $^{6}$, V Krogh ${ }^{1}$, \\ R Luben ${ }^{5}, \mathrm{~N}$ Allen ${ }^{7}, \mathrm{~K}$ Overvad $^{8}$, A Tjønneland ${ }^{9}$, F Clavel-Chapelon $^{3}$, A Thiébaut $^{3}$,

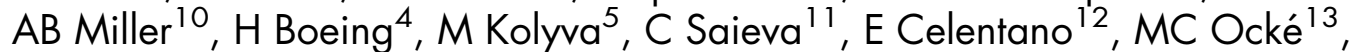 \\ PHM Peeters ${ }^{14}, \mathrm{M} \mathrm{Brustad}^{15}, \mathrm{M} \mathrm{Kumle}^{15}, \mathrm{M}^{15}$ Dorronsoro $^{16}$, A Fernandez Feito ${ }^{17}$, \\ I Mattisson ${ }^{18}$, L Weinehall ${ }^{19}$, E Riboli $^{20}$ and N Slimani ${ }^{20}$ \\ ${ }^{1}$ Epidemiology Unit, National Cancer Institute, Via Venezian 1, 20133 Milan, Italy: ${ }^{2}$ Catalan Institute of Oncology, \\ Barcelona, Spain: ${ }^{3}$ Institute Gustave Roussy, Villejuif, France: ${ }^{4}$ Department of Epidemiology, German Institute of \\ Human Nutrition, Potsdam-Rehbrücke, Germany: ${ }^{5}$ University of Athens, Greece: ${ }^{6}$ Institute of Public Health, University \\ of Cambridge, UK: ${ }^{7}$ Cancer Research UK, Epidemiology Unit, University of Oxford, UK: ${ }^{8}$ Department of \\ Epidemiology and Social Medicine, University of Aarhus, Denmark: ${ }^{9}$ Institute of Cancer Epidemiology, Copenhagen, \\ Denmark: ${ }^{10}$ Division of Clinical Epidemiology, German Cancer Research Centre, Heidelberg, Germany: \\ ${ }^{11}$ Molecular and Nutritional Epidemiology Unit, CSPO, Scientific Institute of Tuscany, Florence, Italy: ${ }^{12}$ Epidemiology \\ Unit, National Cancer Institute, Naples, Italy: ${ }^{13}$ Department for Chronic Diseases Epidemiology, National Institute for \\ Public Health and the Environment, Bilthoven, The Netherlands: ${ }^{14}$ Julius Center for General Practice and Patient \\ Oriented Research, Utrecht, The Netherlands: ${ }^{15}$ Institute of Community Medicine, University of Tromsø, Norway: \\ ${ }^{16}$ Public Health Division of Gipuzkoa, Department of Health of Basque Government, San Sebastian, Spain: ${ }^{17}$ Public \\ Health Directorate, Health Council and Health Services Asturias, Oviedo, Spain: ${ }^{18}$ Department of Medicine, Surgery \\ and Orthopaedics, Lund University, Malmö, Sweden: ${ }^{19}$ Epidemiology and Nutritional Research, Department of \\ Public Health and Clinical Medicine, Umeå University, Sweden: ${ }^{20}$ International Agency for Research on Cancer, \\ Lyon, France
}

\begin{abstract}
Objective: The aim of this study was to compare the quantities of alcohol and types of alcoholic beverages consumed, and the timing of consumption, in centres participating in the European Prospective Investigation into Cancer and Nutrition (EPIC). These centres, in 10 European countries, are characterised by widely differing drinking habits and frequencies of alcohol-related diseases.

Methods: We collected a single standardised 24-hour dietary recall per subject from a random sample of the EPIC cohort (36900 persons initially and 35955 after exclusion of subjects under 35 and over 74 years of age). This provided detailed information on the distribution of alcohol consumption during the day in relation to main meals, and was used to determine weekly consumption patterns. The crude and adjusted (by age, day of week and season) means of total ethanol consumption and consumption according to type of beverage were stratified by centre and sex.

Results: Sex was a strong determinant of drinking patterns in all 10 countries. The highest total alcohol consumption was observed in the Spanish centres (San Sebastian, $41.4 \mathrm{~g} \mathrm{day}^{-1}$ ) for men and in Danish centres (Copenhagen, 20.9 $\mathrm{g} \mathrm{day}^{-1}$ ) for women. The lowest total alcohol intake was in the Swedish centres (Umeå, $10.2 \mathrm{~g} \mathrm{day}^{-1}$ ) in men and in Greek women $\left(3.4 \mathrm{~g} \mathrm{day}^{-1}\right)$. Among men, the main contributor to total alcohol intake was wine in Mediterranean countries and beer in the Dutch, German, Swedish and Danish centres. In most centres, the main source of alcohol for women was wine except for Murcia (Spain), where it was beer. Alcohol consumption, particularly by women, increased markedly during the weekend in nearly all centres. The German, Dutch, UK (general population) and Danish centres were characterised by the highest percentages of alcohol consumption outside mealtimes.

Conclusions: The large variation in drinking patterns among the EPIC centres provides an opportunity to better understand the relationship between alcohol and alcohol-related diseases.
\end{abstract}

Keywords Alcohol consumption 24-Hour dietary recall EPIC study Europe 
Alcohol drinking patterns vary between countries and cultures $^{1}$. Specifically, the type of alcoholic beverage consumed, the proportion of total alcohol consumed during the weekend, the amount of alcohol ingested per drinking occasion and the drinking context (social drinking vs. solitary drinking) vary across cultures and between countries ${ }^{1}$. In Europe, however, drinking patterns seem to be converging, in that traditional patterns have been substituted by newly acquired, more homogenous ones ${ }^{1}$.

Alcohol consumption has been related to increased risk of death by homicide, suicide, and traffic and other accidents $^{2,3}$. Alcohol is a well-established cause of cancer of the oral cavity, larynx, oesophagus and liver ${ }^{4}$, while there is some evidence that it also increases the risk of breast, colon and rectum cancer ${ }^{5,6}$. Furthermore, alcohol consumption increases the risk of cerebrovascular disease (haemorrhagic stroke $)^{7,8}$ and increases blood pressure ${ }^{9-11}$.

By contrast, moderate alcohol consumption may have a protective effect against cardiovascular disease, by increasing high-density lipoproteins ${ }^{9,12,13}$ and by lowering fibrinogen ${ }^{14-16}$ and clotting factors ${ }^{17,18}$.

It is not known whether the overall effect of alcohol on health is related to the type of alcoholic beverage consumed and the drinking pattern ${ }^{19}$. However, it has been suggested ${ }^{20,21}$ that drinking large amounts of alcohol on a single occasion and drinking on an empty stomach may be particularly deleterious, because in these situations the deactivating capacity of alcohol dehydrogenase is overcome, resulting in tissue exposure to high ethanol levels for relatively long periods ${ }^{22}$.

The aim of the present study was to compare patterns of alcohol consumption in the 10 European countries participating in the European Prospective Investigation into Cancer and Nutrition (EPIC) using data from a single 24-hour dietary recall administered to a sub-sample of the whole cohort. Although 24-hour dietary recall provides a good estimation of mean consumption at the group level, the estimation of the habitual diet is poor, making it impossible to distinguish between regular drinkers and non-drinkers.

\section{Methods}

\section{Setting and subjects}

EPIC is a multi-centre prospective study being conducted on half a million adult volunteers enrolled between 1992 and 2000 in 10 Western European countries ${ }^{23}$. Study samples come from varying source populations: cancer screening programmes, blood donor associations and the general population ${ }^{23,24}$. Originally there were 23 centres; however, for statistical analysis the French, UK and Norwegian centres were redefined producing 27 centres for women and 19 for men. The French sample was divided into four geographic regions (North-east, Northwest, South and South coast). For the UK, the 'health- conscious' group, recruited by post, was considered separately, and the cohorts from Cambridge and Oxford, recruited by general practitioners, formed the general population group. For Norway, the various centres were grouped geographically into South \& East (roughly inland) and North \& West (roughly coastal). The Dutch centre of Bilthoven covers Amsterdam, Doetinchem and Maastricht.

In most centres, both sexes were recruited, but women only were recruited in the centres of Norway, France, Utrecht (The Netherlands) and Naples (Italy). The aim of EPIC is to investigate the relationships between diet, nutritional and metabolic characteristics and cancer risk; full details are given elsewhere ${ }^{23}$.

A random sample (36900 subjects), stratified by age, sex and centre, and weighted for expected cancer cases in each stratum, was extracted from the entire EPIC cohort. Subjects under 35 and over 74 years of age were excluded from the sample, leaving a total of 35955 subjects. Between 1995 and 1998 (in Norway between 1999 and 2000), a single 24-hour dietary recall was administered to these subjects (13031 men and 22924 women, aged 3574 years). Invitations to attend interviews were distributed so as to ensure, as far as possible, uniform distribution of interviews by day of the week and season of the year.

\section{Dietary methods}

The interviewer elicited 24-hour dietary recall in a uniform manner using the EPIC-SOFT program ${ }^{25}$, developed for the purpose by the International Agency for Research on Cancer in collaboration with all EPIC centres. The program accepted four different methods of estimating the portion size of the different types of beverage: weight/volume, photographs of different glasses with indications for the level of filling, standard units and household measures. The 24-hour dietary recall data contained detailed information on the distribution of alcohol consumption during the day in relation to main meals. From these data, individual ethanol consumption on the recall day was calculated as the sum of the ethanol content of all of the alcoholic beverages consumed. The ethanol contents of beverages were obtained from food composition tables specific for each participating country.

\section{Classification of alcohol consumption}

Alcoholic beverages were classified into eight groups: wines, fortified wines, beer (including cider), spirits, aniseed drinks, liqueurs, cocktails/punches, and all other alcoholic beverages.

In the present study we analysed only wine, beer/cider, spirits and total ethanol intake, since other categories of alcoholic beverage were consumed extensively only in one or two centres. However, the ethanol content of all alcoholic beverages consumed was used to calculate the total alcohol intake. All alcoholic beverages were also included in calculating the percentage contributions of the different categories to total ethanol intake. 
The times during the day on which alcohol consumption took place were standardised according to the Food Consumption Occasion (FCO) module ${ }^{25}$. These periods or occasions were defined as follows: before breakfast, breakfast, during the morning, before lunch, lunch, after lunch, during the afternoon, before dinner, dinner, after dinner, during the evening/at night.

We defined an alcoholic beverage as drunk outside mealtime if it was drunk on an FCO in which the energy intake was less than $10 \%$ of the total daily energy (excluding energy from alcohol) and at least $5 \mathrm{~g}$ of alcohol was consumed. Alcohol consumption was also analysed in terms of weekday (Monday-Thursday) and weekend (Friday-Sunday) consumption.

\section{Statistical methods}

We calculated crude and adjusted means of the consumption of each beverage category and of total ethanol by centre using a so-called mixture approach, in which covariance analysis took into account the possible confounding effect of age and a weighting procedure ${ }^{26}$ took into account the uneven distribution, among centres, of the interviews by day of the week (weekday vs. weekend) and season. All analyses were performed using the STATA statistical package version 7.0, using analytical weights calculated as the ratio of the expected to the observed number of subjects in each centre and sex with regard to season and day-to-day distribution. Age was included as a continuous variable in the covariance analysis. All analyses were performed separately for men and women.

\section{Results}

Tables 1 and 2 show crude and adjusted means of the ethanol consumption by study centre, stratified by beverage category (wine, beer/cider and spirits) and sex. From these tables it is evident that the adjusted sets of figures do not differ greatly from the crude ones. However, since it is important in the description of alcohol consumption to take into account the possible confounding effect of age, we discuss adjusted means rather than crude ones.

Wine intake varied greatly between centre and according to sex (Tables 1 and 2). For men, wine consumption varied 11-fold across centres (Table 1), being highest in the northern Italian centres (Varese and Turin) and lowest in Sweden (Umeå). In Italy, consumption was twice as high in the northern centres (Turin and Varese) as in the southern centre (Ragusa). Similarly, in Spain wine

Table 1 Crude and adjusted means of wine, beer and spirits intake $\left(\mathrm{g} \mathrm{day}^{-1}\right)$ among men in the 19 European Prospective Investigation into Cancer and Nutrition (EPIC) centres

\begin{tabular}{|c|c|c|c|c|c|c|c|c|c|c|}
\hline \multirow[b]{3}{*}{ Country and centre } & \multirow[b]{3}{*}{$n$} & \multicolumn{3}{|c|}{ Wine } & \multicolumn{3}{|c|}{ Beer } & \multicolumn{3}{|c|}{ Spirits } \\
\hline & & \multirow[b]{2}{*}{ Crude mean } & \multicolumn{2}{|c|}{ Adjusted $^{*}$} & \multirow[b]{2}{*}{ Crude mean } & \multicolumn{2}{|c|}{ Adjusted* } & \multirow[b]{2}{*}{ Crude mean } & \multicolumn{2}{|c|}{ Adjusted* } \\
\hline & & & Mean & SE & & Mean & SE & & Mean & SE \\
\hline \multicolumn{11}{|l|}{ Greece } \\
\hline Greece & 1312 & 117.3 & 118.7 & 6.2 & 69.8 & 87.0 & 12.7 & 5.1 & 5.6 & 0.9 \\
\hline \multicolumn{11}{|l|}{ Spain } \\
\hline Granada & 214 & 145.8 & 146.2 & 15.2 & 112.8 & 126.9 & 31.0 & 8.8 & 8.6 & 2.1 \\
\hline Murcia & 243 & 159.2 & 155.0 & 14.3 & 234.3 & 214.8 & 29.1 & 12.9 & 11.8 & 2.0 \\
\hline Navarra & 444 & 258.1 & 260.5 & 10.5 & 50.2 & 49.4 & 21.5 & 14.1 & 14.6 & 1.5 \\
\hline San Sebastian & 490 & 300.0 & 293.8 & 10.1 & 117.2 & 91.8 & 20.7 & 10.7 & 9.6 & 1.4 \\
\hline Asturias & 386 & 232.2 & 228.7 & 11.3 & 144.4 & 138.1 & 23.1 & 11.5 & 11.2 & 1.6 \\
\hline \multicolumn{11}{|l|}{ Italy } \\
\hline Ragusa & 168 & 140.0 & 141.5 & 17.2 & 29.9 & 12.5 & 35.0 & 1.1 & 0.8 & 2.4 \\
\hline Florence & 271 & 202.4 & 202.4 & 13.5 & 23.0 & 12.3 & 27.6 & 3.3 & 2.9 & 1.9 \\
\hline Turin & 677 & 290.2 & 294.1 & 8.6 & 38.1 & 31.2 & 17.5 & 3.9 & 3.8 & 1.2 \\
\hline Varese & 328 & 298.7 & 305.0 & 12.3 & 28.8 & 32.3 & 25.0 & 5.9 & 5.7 & 1.7 \\
\hline \multicolumn{11}{|l|}{ Germany } \\
\hline Heidelberg & 1033 & 115.8 & 123.1 & 7.0 & 375.8 & 396.9 & 14.2 & 2.9 & 3.3 & 1.0 \\
\hline Potsdam & 1235 & 45.4 & 50.5 & 6.3 & 395.4 & 407.9 & 12.9 & 5.1 & 5.5 & 0.9 \\
\hline \multicolumn{11}{|l|}{ The Netherlands } \\
\hline Bilthoven & 1024 & 61.6 & 60.6 & 7.2 & 373.5 & 347.4 & 14.7 & 11.1 & 10.1 & 1.0 \\
\hline \multicolumn{11}{|l|}{ United Kingdom } \\
\hline General population & 404 & 87.6 & 87.9 & 11.1 & 223.6 & 229.4 & 22.6 & 11.7 & 11.9 & 1.5 \\
\hline 'Health-conscious' & 114 & 61.3 & 58.3 & 20.8 & 196.0 & 218.1 & 42.5 & 2.1 & 1.8 & 2.9 \\
\hline \multicolumn{11}{|l|}{ Denmark } \\
\hline Copenhagen & 1356 & 171.3 & 193.9 & 6.0 & 350.1 & 350.0 & 12.3 & 7.3 & 8.0 & 0.8 \\
\hline Aarhus & 567 & 140.4 & 154.5 & 9.3 & 338.9 & 344.8 & 19.1 & 9.6 & 10.2 & 1.3 \\
\hline \multicolumn{11}{|l|}{ Sweden } \\
\hline Malmö & 1421 & 43.3 & 47.1 & 6.2 & 199.6 & 234.9 & 12.7 & 9.1 & 10.7 & 0.9 \\
\hline Umeå & 1344 & 27.1 & 28.0 & 6.1 & 170.4 & 177.0 & 12.4 & 6.2 & 6.5 & 0.8 \\
\hline
\end{tabular}

SE - standard error.

${ }^{*}$ Adjusted by age, day of the week and season. 
Table 2 Crude and adjusted means of wine, beer and spirits intake $\left(\mathrm{g} \mathrm{day}^{-1}\right)$ among women in the 27 European Prospective Investigation into Cancer and Nutrition (EPIC) centres

\begin{tabular}{|c|c|c|c|c|c|c|c|c|c|c|}
\hline \multirow[b]{3}{*}{ Country and centre } & \multirow[b]{3}{*}{$n$} & \multicolumn{3}{|c|}{ Wine } & \multicolumn{3}{|c|}{ Beer } & \multicolumn{3}{|c|}{ Spirits } \\
\hline & & \multirow[b]{2}{*}{ Crude mean } & \multicolumn{2}{|c|}{ Adjusted $^{*}$} & \multirow[b]{2}{*}{ Crude mean } & \multicolumn{2}{|c|}{ Adjusted $^{*}$} & \multirow[b]{2}{*}{ Crude mean } & \multicolumn{2}{|c|}{ Adjusted ${ }^{*}$} \\
\hline & & & Mean & $\overline{S E}$ & & Mean & $\overline{S E}$ & & Mean & SE \\
\hline \multicolumn{11}{|l|}{ Greece } \\
\hline Greece & 1374 & 23.1 & 21.5 & 3.9 & 17.2 & 24.7 & 3.8 & 0.7 & 1.1 & 0.4 \\
\hline \multicolumn{11}{|l|}{ Spain } \\
\hline Granada & 300 & 13.7 & 17.7 & 8.4 & 27.2 & 26.0 & 8.2 & 0.4 & 0.1 & 0.9 \\
\hline Murcia & 304 & 31.8 & 29.4 & 8.3 & 108.4 & 114.6 & 8.2 & 1.2 & 1.1 & 0.9 \\
\hline Navarra & 271 & 34.4 & 33.1 & 8.8 & 5.7 & 4.4 & 8.6 & 0.2 & 0.2 & 1.0 \\
\hline San Sebastian & 244 & 65.3 & 64.2 & 9.3 & 14.7 & 10.2 & 9.1 & 0.8 & 0.8 & 1.0 \\
\hline Asturias & 324 & 41.9 & 42.8 & 8.1 & 29.7 & 29.4 & 7.9 & 0.5 & 0.4 & 0.9 \\
\hline \multicolumn{11}{|l|}{ Italy } \\
\hline Ragusa & 138 & 42.1 & 34.7 & 12.4 & 12.9 & 5.6 & 12.1 & 0.0 & 0.0 & 1.4 \\
\hline Naples & 403 & 61.9 & 72.8 & 7.2 & 9.6 & 7.0 & 7.1 & 0.2 & 0.2 & 0.8 \\
\hline Florence & 785 & 69.3 & 71.0 & 5.2 & 9.4 & 10.3 & 5.1 & 0.5 & 0.5 & 0.6 \\
\hline Turin & 392 & 95.5 & 102.9 & 7.3 & 10.1 & 9.7 & 7.2 & 0.6 & 0.7 & 0.8 \\
\hline Varese & 794 & 67.7 & 67.1 & 5.2 & 8.5 & 9.3 & 5.0 & 0.7 & 0.7 & 0.6 \\
\hline \multicolumn{11}{|l|}{ France } \\
\hline South coast & 612 & 96.7 & 101.2 & 5.9 & 9.9 & 11.9 & 5.8 & 1.4 & 1.2 & 0.7 \\
\hline South & 1396 & 86.3 & 94.1 & 3.9 & 10.9 & 13.2 & 3.8 & 1.5 & 2.1 & 0.4 \\
\hline North-west & 622 & 97.7 & 103.7 & 5.8 & 17.9 & 20.0 & 5.7 & 1.9 & 2.0 & 0.6 \\
\hline North-east & 2009 & 96.4 & 102.2 & 3.3 & 23.2 & 27.3 & 3.2 & 1.8 & 1.9 & 0.4 \\
\hline \multicolumn{11}{|l|}{ Germany } \\
\hline Heidelberg & 1087 & 93.7 & 99.5 & 4.5 & 75.8 & 70.4 & 4.4 & 1.2 & 1.0 & 0.5 \\
\hline Potsdam & 1063 & 59.5 & 58.8 & 4.5 & 48.7 & 43.6 & 4.4 & 1.3 & 1.0 & 0.5 \\
\hline \multicolumn{11}{|l|}{ The Netherlands } \\
\hline Bilthoven & 1086 & 64.1 & 59.8 & 4.5 & 54.2 & 49.1 & 4.4 & 2.8 & 2.4 & 0.5 \\
\hline Utrecht & 1874 & 68.6 & 71.2 & 3.4 & 14.9 & 17.4 & 3.3 & 3.1 & 3.3 & 0.4 \\
\hline \multicolumn{11}{|l|}{ United Kingdom } \\
\hline General population & 571 & 84.7 & 91.5 & 6.1 & 20.4 & 20.3 & 6.0 & 6.1 & 7.4 & 0.7 \\
\hline 'Health-conscious' & 197 & 51.9 & 61.7 & 10.4 & 28.1 & 21.1 & 10.1 & 3.1 & 4.5 & 1.2 \\
\hline \multicolumn{11}{|l|}{ Denmark } \\
\hline Copenhagen & 1485 & 131.2 & 146.6 & 3.8 & 80.0 & 90.4 & 3.7 & 3.9 & 4.7 & 0.4 \\
\hline Aarhus & 510 & 109.6 & 120.1 & 6.4 & 92.7 & 98.7 & 6.3 & 3.6 & 4.4 & 0.7 \\
\hline \multicolumn{11}{|l|}{ Sweden } \\
\hline Malmö & 1711 & 47.7 & 53.7 & 3.6 & 73.6 & 79.5 & 3.5 & 1.8 & 2.1 & 0.4 \\
\hline Umeå & 1574 & 32.1 & 32.5 & 3.7 & 56.3 & 58.3 & 3.6 & 1.4 & 1.5 & 0.4 \\
\hline \multicolumn{11}{|l|}{ Norway } \\
\hline South \& East & 1136 & 55.4 & 55.0 & 4.4 & 45.2 & 43.2 & 4.3 & 3.0 & 2.8 & 0.5 \\
\hline North \& West & 662 & 54.9 & 50.6 & 5.7 & 33.3 & 27.4 & 5.6 & 2.3 & 1.7 & 0.6 \\
\hline
\end{tabular}

SE - standard error.

${ }^{*}$ Adjusted by age, day of the week and season.

intake was about one-and-half times higher in the northern EPIC centres (Asturias, San Sebastian and Navarra) than in the southern ones (Murcia and Granada).

Women (Table 2) drank much less wine than did men in the Mediterranean centres of Spain, Greece and Italy, consuming, respectively, six, five and four times less than men. By contrast, wine consumption among women was equal to or higher than that of men in the UK, The Netherlands and Sweden. Overall, wine consumption among women varied eight-fold, being highest in the Danish centres and lowest in southern Spain (Granada).

Mean beer/cider intake is shown in Tables 1 and 2 for men and women, respectively. Among men, beer/cider intake varied 33-fold, being highest in the German, Dutch and Danish centres and lowest in the Italian centres. Beer/cider consumption was lower in women than in men and varied 26-fold, being particularly high in Murcia (Spain) followed by Denmark, and particularly low in
Mediterranean countries (Navarra and San Sebastian in Spain, Italy, South of France). Furthermore, there was a clear centre-within-countries variation in beer/cider intake among women in The Netherlands (Bilthoven, Utrecht), Germany (Heidelberg, Potsdam), Sweden (Malmö, Umeå) and Norway (South \& East, North \& West).

Among men, intake of spirits varied 18-fold (Table 1), being highest in the Spanish centres (especially Navarra and Murcia) and the general UK population, and lowest in Italy (especially Ragusa).

In general, women consumed very low quantities of spirits (Table 2), the exceptions being the UK and Danish centres. Very small quantities of spirits, generally less than $1 \mathrm{~g} \mathrm{day}^{-1}$, were consumed by women in the Italian and Spanish centres.

Total alcohol intake is shown in Tables 3 and 4 for men and women, respectively. Among men, total alcohol consumption varied four-fold overall, being highest in San 
Table 3 Crude and adjusted means of total ethanol intake $\left(\right.$ g day $^{-1}$ ) among men in the 19 European Prospective Investigation into Cancer and Nutrition (EPIC) centres

\begin{tabular}{|c|c|c|c|c|}
\hline \multirow[b]{3}{*}{ Country and centre } & \multirow[b]{3}{*}{$n$} & \multicolumn{3}{|c|}{ Total ethanol } \\
\hline & & \multirow[b]{2}{*}{ Crude mean } & \multicolumn{2}{|c|}{ Adjusted ${ }^{*}$} \\
\hline & & & Mean & SE \\
\hline \multicolumn{5}{|l|}{ Greece } \\
\hline Greece & 1312 & 18.7 & 19.8 & 0.9 \\
\hline \multicolumn{5}{|l|}{ Spain } \\
\hline Granada & 214 & 24.0 & 24.5 & 2.2 \\
\hline Murcia & 243 & 29.8 & 28.2 & 2.1 \\
\hline Navarra & 444 & 37.6 & 38.1 & 1.5 \\
\hline San Sebastian & 490 & 43.6 & 41.4 & 1.5 \\
\hline Asturias & 386 & 36.4 & 35.6 & 1.6 \\
\hline \multicolumn{5}{|l|}{ Italy } \\
\hline Ragusa & 168 & 14.7 & 14.0 & 2.5 \\
\hline Florence & 271 & 21.4 & 20.8 & 2.0 \\
\hline Turin & 677 & 30.0 & 30.0 & 1.2 \\
\hline Varese & 328 & 31.2 & 31.9 & 1.8 \\
\hline \multicolumn{5}{|l|}{ Germany } \\
\hline Heidelberg & 1033 & 27.8 & 29.5 & 1.0 \\
\hline Potsdam & 1235 & 22.3 & 23.4 & 0.9 \\
\hline \multicolumn{5}{|l|}{ The Netherlands } \\
\hline Bilthoven & 1024 & 25.1 & 23.6 & 1.0 \\
\hline \multicolumn{5}{|l|}{ United Kingdom } \\
\hline General population & 404 & 21.2 & 21.5 & 1.6 \\
\hline ‘Health-conscious’ & 114 & 15.5 & 16.5 & 3.0 \\
\hline \multicolumn{5}{|l|}{ Denmark } \\
\hline Copenhagen & 1356 & 34.6 & 37.2 & 0.9 \\
\hline Aarhus & 567 & 31.8 & 33.7 & 1.3 \\
\hline \multicolumn{5}{|l|}{ Sweden } \\
\hline Malmö & 1421 & 13.5 & 15.9 & 0.9 \\
\hline Umeå & 1344 & 9.7 & 10.2 & 0.9 \\
\hline
\end{tabular}

SE - standard error.

${ }^{*}$ Adjusted by age, day of the week and season.

Sebastian (Spain) and lowest in Umeå (Sweden). In general, Mediterranean men consumed much more ethanol than Mediterranean women, ranging from 2.7 times more in Florence (Italy) to nine times more in Navarra (Spain); among the non-Mediterranean populations, the range was 1.7 (UK, general population) to 2.8 (Potsdam, Germany) (Table 3).

Among women, total alcohol consumption varied sixfold overall, being highest in the Danish centres (Aarhus and Copenhagen) and lowest in Greece, Granada (Spain) and Ragusa (Italy) (Table 4).

Figures $1 \mathrm{a}$ and $1 \mathrm{~b}$ show the main sources of alcohol intake by centre for men and women, respectively. Among men, the main source of alcohol in the Mediterranean centres was wine: constituting $88-94 \%$ of the total in the Italian centres, 59-75\% in the Spanish centres, and 56\% in Greece. Beer was the main source of alcohol for men in the German (range 53-69\%), Dutch (59\%), Swedish (range 45-50\%) and UK (range 41-62\%) centres. For Swedish men, the contribution of spirits to total alcohol intake was very high (20.2\% in Malmö and 21.6\% in Umeå) and was also high in the UK general population (15.9\%) and the Dutch (13.2\%), Spanish (range 8.1-14.8\%) and Greek (9\%) centres. In Greece, $20.3 \%$ of alcohol intake
Table 4 Crude and adjusted means of total ethanol intake $\left(\right.$ g day $^{-1}$ ) among women in the 27 European Prospective Investigation into Cancer and Nutrition (EPIC) centres

\begin{tabular}{|c|c|c|c|c|}
\hline \multirow[b]{3}{*}{ Country and centre } & \multirow[b]{3}{*}{$n$} & \multicolumn{3}{|c|}{ Total ethanol } \\
\hline & & \multirow[b]{2}{*}{ Crude mean } & \multicolumn{2}{|c|}{ Adjusted* } \\
\hline & & & Mean & SE \\
\hline \multicolumn{5}{|l|}{ Greece } \\
\hline Greece & 1374 & 3.2 & 3.4 & 0.5 \\
\hline \multicolumn{5}{|l|}{ Spain } \\
\hline Granada & 300 & 3.4 & 3.5 & 1.0 \\
\hline Murcia & 304 & 7.5 & 7.4 & 1.0 \\
\hline Navarra & 271 & 4.4 & 4.2 & 1.0 \\
\hline San Sebastian & 244 & 8.0 & 7.8 & 1.1 \\
\hline Asturias & 324 & 6.6 & 6.7 & 1.0 \\
\hline \multicolumn{5}{|l|}{ Italy } \\
\hline Ragusa & 138 & 4.7 & 3.7 & 1.5 \\
\hline Naples & 403 & 6.8 & 7.6 & 0.9 \\
\hline Florence & 785 & 7.3 & 7.6 & 0.6 \\
\hline Turin & 392 & 9.9 & 10.7 & 0.9 \\
\hline Varese & 794 & 7.1 & 7.1 & 0.6 \\
\hline \multicolumn{5}{|l|}{ France } \\
\hline South coast & 612 & 10.8 & 11.6 & 0.7 \\
\hline South & 1396 & 9.7 & 10.6 & 0.5 \\
\hline North-west & 622 & 11.6 & 12.6 & 0.7 \\
\hline North-east & 2009 & 11.5 & 12.5 & 0.4 \\
\hline \multicolumn{5}{|l|}{ Germany } \\
\hline Heidelberg & 1087 & 13.0 & 13.3 & 0.5 \\
\hline Potsdam & 1063 & 8.6 & 8.4 & 0.5 \\
\hline \multicolumn{5}{|l|}{ The Netherlands } \\
\hline Bilthoven & 1086 & 11.0 & 10.3 & 0.5 \\
\hline Utrecht & 1874 & 11.5 & 11.9 & 0.4 \\
\hline \multicolumn{5}{|l|}{ United Kingdom } \\
\hline General population & 571 & 11.8 & 12.9 & 0.7 \\
\hline 'Health-conscious' & 197 & 7.7 & 8.6 & 1.2 \\
\hline \multicolumn{5}{|l|}{ Denmark } \\
\hline Copenhagen & 1485 & 18.6 & 20.9 & 0.4 \\
\hline Aarhus & 510 & 16.9 & 18.5 & 0.8 \\
\hline \multicolumn{5}{|l|}{ Sweden } \\
\hline Malmö & 1711 & 7.7 & 8.6 & 0.4 \\
\hline Umeå & 1574 & 5.5 & 5.6 & 0.4 \\
\hline \multicolumn{5}{|l|}{ Norway } \\
\hline South \& East & 1136 & 8.3 & 8.2 & 0.5 \\
\hline North \& West & 662 & 7.8 & 7.1 & 0.7 \\
\hline
\end{tabular}

SE - standard error.

${ }^{*}$ Adjusted by age, day of the week and season.

was in the form of aniseed drinks, while in the Spanish centres of Navarra and San Sebastian $8.3 \%$ and $6.5 \%$, respectively, of the total came from liqueurs; in Granada (Spain), 6.9\% came from cocktails and punches.

For women, the main source of alcohol was wine in all study centres except Murcia (Spain), and in this respect they clearly differed from men. The proportion of ethanol drunk as wine ranged from $86-88.8 \%$ in the Italian centres to $42.8 \%$ in Murcia. The contribution of beer to total intake by women was high in Murcia (46\%) and the Swedish (range 25.6-26.6\%) centres. The contribution of spirits to the total intake of females was highest in the UK centres (14.1-16.3\%), followed by the Norwegian centres (9.19.3\%) and Utrecht, The Netherlands (8.6\%). In the French centres, the respective contributions of fortified wines, beer and spirits to the female total were similar. The consumption of aniseed drinks was high ( $7.5 \%$ of total) 
1292

S Sieri et al.
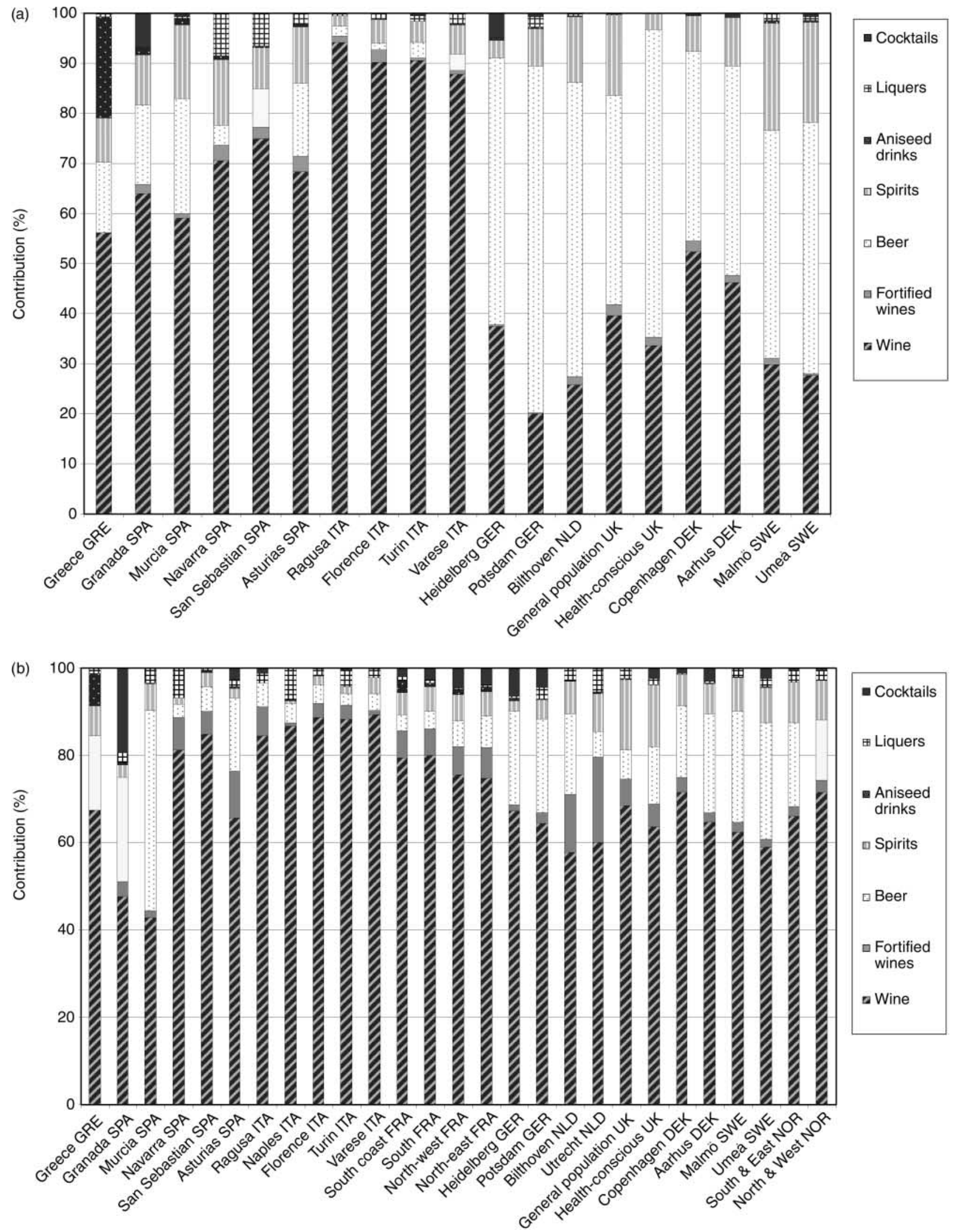

Fig. 1 Percentage contribution of alcoholic beverages to total ethanol intake in the European Prospective Investigation into Cancer and Nutrition (EPIC): (a) men in 19 centres; (b) women in 27 centres. Abbreviations: GRE - Greece; SPA - Spain; ITA - Italy; GER Germany; NLD - The Netherlands; UK - United Kingdom; DEK - Denmark; SWE - Sweden; NOR - Norway 

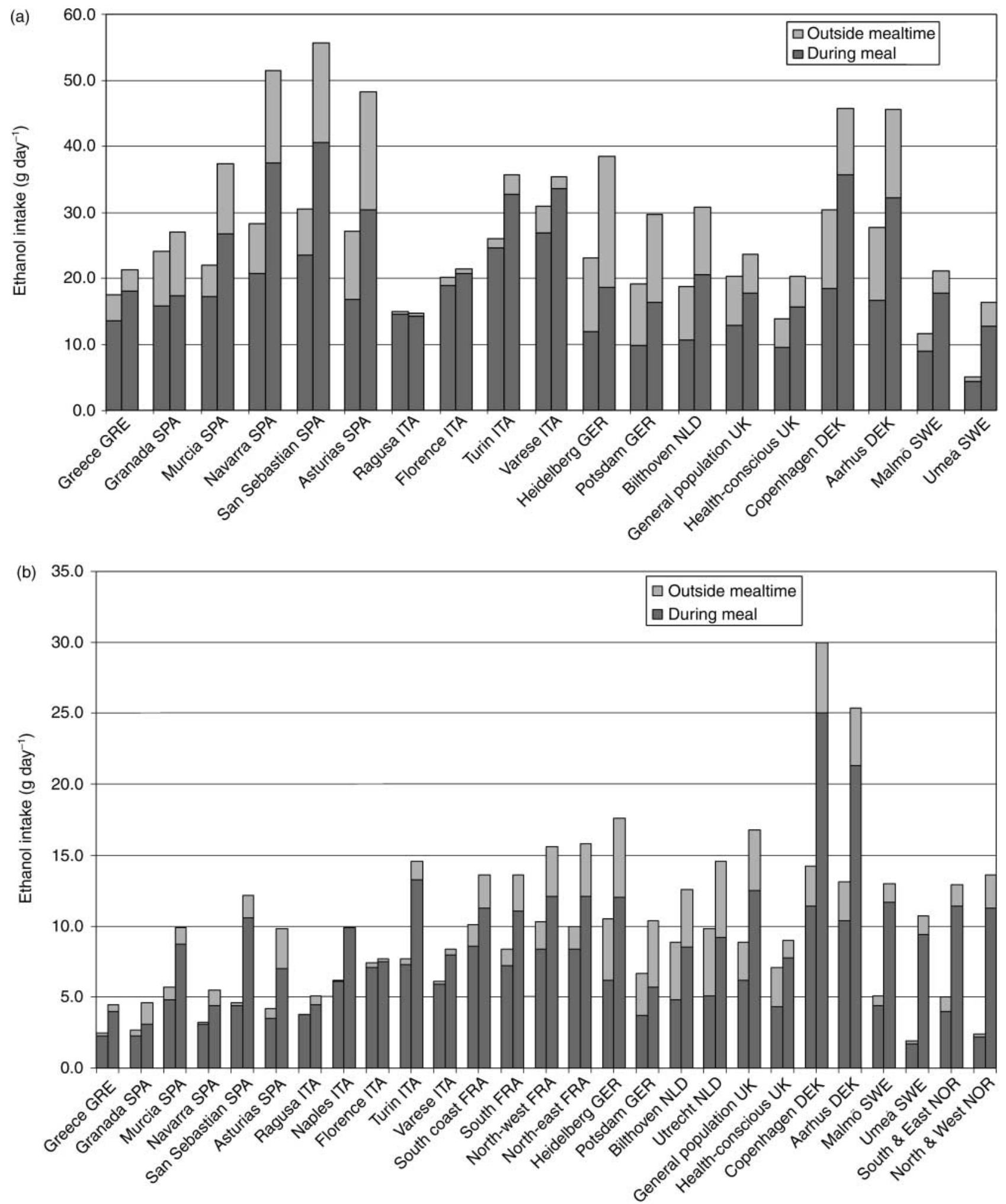

Fig. 2 Adjusted* means of daily ethanol intake during weekdays and at the weekend, during meals and outside mealtimes, in the European Prospective Investigation into Cancer and Nutrition (EPIC): (a) men in 19 centres; (b) women in 27 centres. *Adjusted by age and season; first column - intake during weekdays (Monday-Thursday); second column - intake at the weekend (Friday-Sunday). Abbreviations: GRE - Greece; SPA - Spain; ITA - Italy; GER - Germany; NLD - The Netherlands; UK - United Kingdom; DEK - Denmark; SWE - Sweden; NOR - Norway 
among Greek women, whereas women of Utrecht (19.7\% of total) followed by those in Asturias and Navarra (Spain) consumed the most fortified wines.

Figures $2 \mathrm{a}$ and $2 \mathrm{~b}$ show, for men and women, respectively, the consumption of alcohol according to day of the week (Monday-Thursday vs. Friday-Sunday) during and outside main mealtimes. There was a marked increase in alcohol consumption at the weekends among men in Sweden, especially Umeå (more than a three-fold increase) and Malmö, and also in the north of Spain (Asturias, Navarra, and San Sebastian, 1.8-fold increase overall). For Ragusa, Florence and Varese in Italy, Granada in Spain and Potsdam in Germany, consumption varied little between weekdays and the weekend.

Men in the German, Dutch and Danish study centres, Asturias and Granada in Spain and the UK general population consumed more than $30 \%$ of the total outside mealtimes; while men in Italy, especially Ragusa and Turin (98.6\% and 95.2\%, respectively), consumed most of their alcohol with meals. In the Spanish centres of Asturias, Murcia, Navarra and San Sebastian, the weekend increase in consumption occurred mainly outside mealtimes, whereas in the other study centres, the weekend increase in alcohol intake occurred both at mealtimes and outside mealtimes.

In general, weekend increases in alcohol intake were greater in women than in men, with an increase in weekend drinking among women in all centres except Florence (Italy). The phenomenon was most marked in Umeå (Sweden) and in the Norwegian North \& West centre (greater than five-fold) and was also prominent in San Sebastian (Spain), Malmö (Sweden) and the Norwegian South \& East centres (greater than 2.5-fold).

Women in the Dutch centres and Potsdam (Germany) consumed about $40 \%$ of their alcohol outside mealtimes, followed by Heidelberg (Germany) and the UK 'healthconscious' population (more than 30\%), whereas Italian women from Naples, Ragusa and Florence consumed less than about 3\% outside mealtimes.

In the Spanish centres of Asturias, Granada, Navarra and San Sebastian, and in the North \& West of Norway, the weekend increase was mainly due to consumption outside mealtimes. By contrast, women of the UK 'healthconscious' group increased their mealtime drinking at weekends and actually decreased their out-of-mealtime drinking, although the total effect was a weekend increase.

\section{Discussion}

The present study is the first to compare alcohol consumption in a large and heterogeneous sample of Western Europeans, using a detailed and standardised approach. Specifically, it compares patterns of alcohol consumption in terms of total ethanol intake, type of alcoholic beverage consumed, context of consumption (mealtimes and outside mealtimes) and distribution of consumption during the week, in a selected sample of adults from EPIC centres in 10 European countries. This information was collected by 24-hour dietary recalls ${ }^{25}$.

We found that the type of alcoholic beverage consumed differed between the sexes and between study centres. Among men, wine was consumed mainly in the Italian and Spanish centres, with some regional differences in that more wine was consumed in the northern Italian and northern Spanish centres than in the southern ones. By contrast, beer was consumed mainly by men in the German, Dutch and Danish centres (almost $400 \mathrm{~g} \mathrm{day}^{-1}$ ), whereas the lowest beer consumption was in the Italian centres (about 16 times lower than in the high consumption northern European centres).

In general, women drank less than men and also consumed different types of beverages. We found large differences between centres in terms of the quantity of alcohol consumed by women, while differences in wine consumption were less marked. The largest quantities of beer were consumed by women in Murcia (Spain), the Danish centres, Heidelberg (Germany) and Malmö (Sweden). In the Murcia centre, the higher mean consumption seems to be due to the low percentage of non-consumers (from EPIC Food Frequency Questionnaire analysis; data not shown).

These findings are only in partial agreement with those of a previous study on alcohol consumption in the European Community ${ }^{1}$. In that study, which evaluated the frequency of alcohol drinking, the Mediterranean countries were characterised mainly by wine consumption, whereas people in northern Europe mainly drank beer $^{1}$. In our study this was only really true for men, since, for all study centres except Murcia (Spain), wine contributed more to women's total alcohol intake than all other sources combined. Possible reasons for these differences may be differences in the sampling or assessment methods.

The European Community study ${ }^{1}$ found that the frequency of wine consumption by women was much lower than that of men in the countries of southern Europe. This is mirrored by our finding that women consumed much less total ethanol than men in the Mediterranean countries, whereas in central and northern Europe, the total ethanol consumption of women was not far behind that of men. The previous study also found that patterns of beer intake were similar to those for total alcohol consumption, but in our study women drank very much less beer than men in all centres.

Several studies have reported sex differences regarding alcohol use similar to ours ${ }^{27-29}$. Women on average consume less alcohol than men ${ }^{30,31}$, drink more slowly and more often with meals ${ }^{27}$ and have different preferences to men with regard to alcoholic beverages $^{30,32}$. These differences in drinking habits might explain the lower incidence of several alcohol-related diseases in women than in men ${ }^{33,34}$. Nevertheless, despite 
this, for equal alcohol intake, women have higher blood levels of ethanol than men ${ }^{35,36}$ and ethanol bioavailability is much greater in women than men because women have lower gastric alcohol dehydrogenase activity ${ }^{22}$ and the volume of distribution of ethanol is also lower ${ }^{37}$.

Another finding of our study was that European centres differed in the distribution of alcohol consumption during the week and whether or not it was consumed mainly at mealtimes. In Italy, both sexes drank most of their alcohol during meals, whereas in most other countries more alcohol was drunk outside main meals, especially in Germany and The Netherlands, as reported previously ${ }^{1}$. The consumption pattern was not very different in the majority of centres when weekdays and weekends were considered separately. However, in most Spanish centres for both sexes, and in the Norwegian North \& West centre for women, the proportion of alcohol consumed outside mealtimes increased during the weekend; while among women of the UK 'health-conscious' group, the proportion of alcohol drunk outside mealtimes decreased during the weekend.

Drinking large amounts outside mealtimes may be particularly harmful because the alcohol is absorbed quickly as the stomach is empty and metabolising enzymes will be quickly saturated. One study, which pooled the data of several Italian epidemiological studies, found that drinking wine outside mealtimes was related to increased mortality from all causes ${ }^{38}$.

In agreement with the results of the Dutch National Food Survey ${ }^{39}$ we found that, for both sexes, alcohol consumption was higher at weekends. However, this phenomenon was most evident in women, for whom drinking increased 1.6-fold at weekends compared with weekdays.

A disadvantage of the 24-hour recall interview is that it provides a poor estimate of habitual diet at the individual level, although it does provide a good estimate of overall diet at the group level. For this reason the method cannot distinguish between regular drinkers, occasional drinkers and non-drinkers. Faced with dietary data based on only one day's individual punctual measurement, the mean and not rank statistics like quartiles or median seems the more appropriate way to describe and compare alcohol intake at group level. A limitation of the study is that selected cohorts from restricted regions were considered, so that the overall figures for alcohol consumption we found may not accurately reflect consumption at the country level $^{24,40}$.

To conclude, our study was successful in revealing in detail the marked differences in patterns of alcohol consumption among the European centres considered. The most commonly consumed alcoholic beverages were wine by southern European men and beer by men in other countries. Women from all but one centre preferred wine. No clear geographic patterns were discerned for spirits consumption. Increased weekend drinking seems to be a characteristic of northern Europe, while alcohol consumption is generally restricted to mealtimes in Mediterranean countries. These findings form a useful basis for future prospective studies on alcohol-related diseases.

\section{Acknowledgements}

The work described in this paper was carried out with financial support of the 'Europe Against Cancer' Programme of the European Commission (SANCO); Ligue contre le Cancer (France); Société $3 \mathrm{M}$ (France); Mutuelle Générale de l'Education Nationale; Institut National de la Santé et de la Recherche Médicale (INSERM); Institute Gustave Roussy; German Cancer Aid; German Cancer Research Centre; German Federal Ministry of Education and Research; Danish Cancer Society; Health Research Fund (FIS) of the Spanish Ministry of Health; the Spanish Regional Governments of Andalucia, Asturias, Basque Country, Murcia and Navarra; Cancer Research UK; Medical Research Council, UK; Stroke Association, UK; British Heart Foundation; Department of Health, UK; Food Standards Agency, UK; Wellcome Trust, UK; Greek Ministry of Health; Greek Ministry of Education; Italian Association for Research on Cancer; Italian National Research Council; Dutch Ministry of Public Health, Welfare and Sports; Dutch Prevention Funds; LK Research Funds; Dutch ZON (Zorg Onderzoek Nederland); World Cancer Research Fund; Swedish Cancer Society; Swedish Scientific Council; Regional Government of Skane, Sweden; Norwegian Cancer Society; Norwegian Research Council. Partial support for the publication of this supplement was provided by the Centre de Recherche et d'Information Nutritionnelles (CERIN).

In addition, we wish to thank all study participants for their co-operation and all interviewers who participated in the fieldwork studies in each EPIC centre.

\section{References}

1 Hupkens CL, Knibbe RA, Drop MJ. Alcohol consumption in the European community: uniformity and diversity in drinking patterns. Addiction 1993; 88(10): 1391-404.

2 English D. The Quantification of Drug-Caused Morbidity and Mortality in Australia. Part 1-2. Canberra: Commonwealth Department of Human Services and Health, Australian Government Printing Office, 1995.

3 World Health Organization (WHO). The World Health Report. Geneva: WHO, 1997.

4 International Agency for Research on Cancer (IARC). Alcohol Drinking. IARC Monographs on the Evaluation of Carcinogenic Risks to Humans. Vol. 44. Lyon: IARC, 1988.

5 World Cancer Research Fund (WCRF)/American Institute for Cancer Research (AICR). Food, Nutrition and the Prevention of Cancer: A Global Perspective. Washington, DC: WCRF/AICR, 1997.

6 Smith-Warner SA, Spiegelman D, Yaun SS, van den Brandt PA, Folsom AR, Goldbohm RA, et al. Alcohol and breast cancer in women: a pooled analysis of cohort studies. J. Am. Med. Assoc. 1998; 279(7): 535-40.

7 Donahue RP, Abbott RD, Reed DM, Yano K. Alcohol and 
haemorrhagic stroke. The Honolulu Heart Program. J. Am. Med. Assoc. 1986; 255(17): 2311-4.

8 Stampfer MJ, Colditz GA, Willett WC, Speizer FE, Hennekens $\mathrm{CH}$. A prospective study of moderate alcohol consumption and the risk of coronary disease and stroke in women. N. Engl.J. Med. 1988; 319(5): 267-73.

9 Keil U, Chambless LE, Filipiak B, Hartel U. Alcohol intake and blood pressure and its interaction with smoking and other behaviour variables: results from the MONICA Augsburg survey 1984-1985. J. Hypertens. 1991; 9: 491-8.

10 Keil U, Swales J, Grobbee D. Alcohol consumption and its relation to hypertension. Cardiovasc. Risk Factors 1993; 3: 189-200.

11 Klatsky AL. Alcohol and hypertension. Clin. Chim. Acta 1996; 246(1-2): 91-105.

12 Criqui MH, Cowan LD, Tyroler HA, Bangdiwala S, Heiss G, Wallace RB, et al. Lipoproteins as mediators for the effects of alcohol consumption and cigarette smoking on cardiovascular mortality: results from the Lipid Research Clinics Follow-up Study. Am. J. Epidemiol. 1987; 126(4): 629-37.

13 Suh I, Jee SH, Kim HC, Nam CM, Kim IS, Appel LJ. Low serum cholesterol and haemorrhagic stroke in men: Korea Medical Insurance Corporation Study. Lancet 2001; 357(9260): $922-5$.

14 Hein HO, Suadicani P, Gyntelberg F. Alcohol consumption, serum low density lipoprotein cholesterol concentration, and risk of ischaemic heart disease: six-year follow up in the Copenhagen male study. Br. Med. J. 1996; 312(7033): $736-41$.

15 Laug WE. Ethyl alcohol enhances plasminogen activator secretion by endothelial cells. J. Am. Med. Assoc. 1983; 250(6): 772-6.

16 Krobot K, Hense HW, Cremer P, Eberle E, Keil U. Determinants of plasma fibrinogen: relation to body weight, waist-to-hip ratio, smoking, alcohol, age, and sex. Results from the second MONICA Augsburg survey 1989-1990. Arterioscler. Thromb. 1992; 12(7): 780-8.

17 Renaud S, de Lorgeril M. Wine, alcohol, platelets, and the French paradox for coronary heart disease. Lancet 1992; 339(8808): 1523-6.

18 Ridker PM, Vaughan DE, Stampfer MJ, Glynn RJ, Hennekens $\mathrm{CH}$. Association of moderate alcohol consumption and plasma concentration of endogenous tissue-type plasminogen activator. J. Am. Med. Assoc. 1994; 272(12): 929-33.

19 Fillmore KM, Golding JM, Graves KL, Kniep S, Leino EV, Romelsjo A, et al. Alcohol consumption and mortality. I. Characteristics of drinking groups. Addiction 1998; 93(2): 183-203.

20 Kauhanen J, Kaplan GA, Goldberg DE, Salonen JT. Beer binging and mortality: results from the Kuopio ischaemic heart disease risk factor study, a prospective populationbased study. Br. Med. J. 1997; 315(7112): 846-51.

21 McElduff P, Dobson AJ. How much alcohol and how often? Population-based case-control study of alcohol consumption and risk of a major coronary event. Br. Med. J. 1997; 314(7088): 1159-64.

22 Frezza M, di Padova C, Pozzato G, Terpin M, Baraona E, Lieber CS. High blood alcohol levels in women. The role of decreased gastric alcohol dehydrogenase activity and firstpass metabolism. N. Engl. J. Med. 1990; 322(2): 95-9.
23 Riboli E, Kaaks R. The EPIC Project: rationale and study design. European Prospective Investigation into Cancer and Nutrition. Int. J. Epidemiol. 1997; 26(Suppl. 1): S6-14.

24 Riboli E, Hunt KJ, Slimani N, Ferrari P, Norat T, Fahey M, et al. European Prospective Investigation into Cancer and Nutrition (EPIC): study populations and data collection. Public Health Nutr. 2002; 5(6B): 1113-24.

25 Slimani N, Ferrari P, Ocké M, Welch A, Boeing H, Liere M, et al. Standardisation of the 24-hour diet recall calibration method used in the European Prospective Investigation into Cancer and Nutrition (EPIC): general concepts and preliminary results. Eur.J. Clin. Nutr. 2000; 54(12): 900-17.

26 Gould W. Stata Corporation. Clarification on analytic weights with linear regression. Stata Tech. Bull. 1999; 20.

27 Gomberg ES. Recent developments in alcoholism: gender issues. Recent Dev. Alcohol. 1993; 11: 95-107.

28 Gomberg ES. Women and alcohol: use and abuse. J. Nerv. Ment. Dis. 1993; 181(4): 211-9.

29 Jang KL, Livesley WJ, Vernon PA. Gender-specific etiological differences in alcohol and drug problems: a behavioural genetic analysis. Addiction 1997; 92(10): 1265-76.

30 Dawson DA, Archer L. Gender differences in alcohol consumption: effects of measurement. Br. J. Addict. 1992; 87(1): 119-23.

31 Storm T, Cutler RE. Observations of drinking in natural settings: Vancouver beer parlors and cocktail lounges. J. Stud. Alcohol. 1981; 42(11): 972-97.

32 Klatsky AL, Armstrong MA, Kipp H. Correlates of alcoholic beverage preference: traits of persons who choose wine, liquor or beer. Br.J. Addict. 1990; 85(10): 1279-89.

33 Parkin DM, Whelan SL, Ferlay J, Raymond L, Young J, eds. Cancer Incidence in Five Continents. Vol. VII. IARC Scientific Publication No. 143. Lyon: International Agency for Research on Cancer (IARC), 1997.

34 World Health Organization (WHO). Annual Epidemiological and Vital Statistics. Geneva: WHO, 1995.

35 Dubowski K. Human pharmacokinetics of ethanol. I. Peak blood concentrations and elimination in male and female subjects. Alcohol. Tech. Rep. 1976; 5: 55-63.

36 Mishra L, Sharma S, Potter JJ, Mezey E. More rapid elimination of alcohol in women as compared to their male siblings. Alcohol. Clin. Exp. Res. 1989; 13(6): 752-4.

37 Arthur MJ, Lee A, Wright R. Sex differences in the metabolism of ethanol and acetaldehyde in normal subjects. Clin. Sci. (Colch.) 1984; 67(4): 397-401.

38 Trevisan M, Schisterman E, Mennotti A, Farchi G, Conti S. Drinking pattern and mortality: the Italian risk factor and life expectancy pooling project. Ann. Epidemiol. 2001; 11(5): $312-9$.

39 Veenstra J, Schenkel JA, Erp-Baart AM, Brants HA, Hulshof $\mathrm{KF}$, Kistemaker C, et al. Alcohol consumption in relation to food intake and smoking habits in the Dutch National Food Consumption Survey. Eur. J. Clin. Nutr. 1993; 47(7): 482-9.

40 Slimani N, Kaaks R, Ferrari P, Casagrande C, Clavel-Chapelon F, Lotze G, et al. European Prospective Investigation into Cancer and Nutrition (EPIC) calibration study: rationale, design and population characteristics. Public Health Nutr. 2002; 5(6B): $1125-45$. 